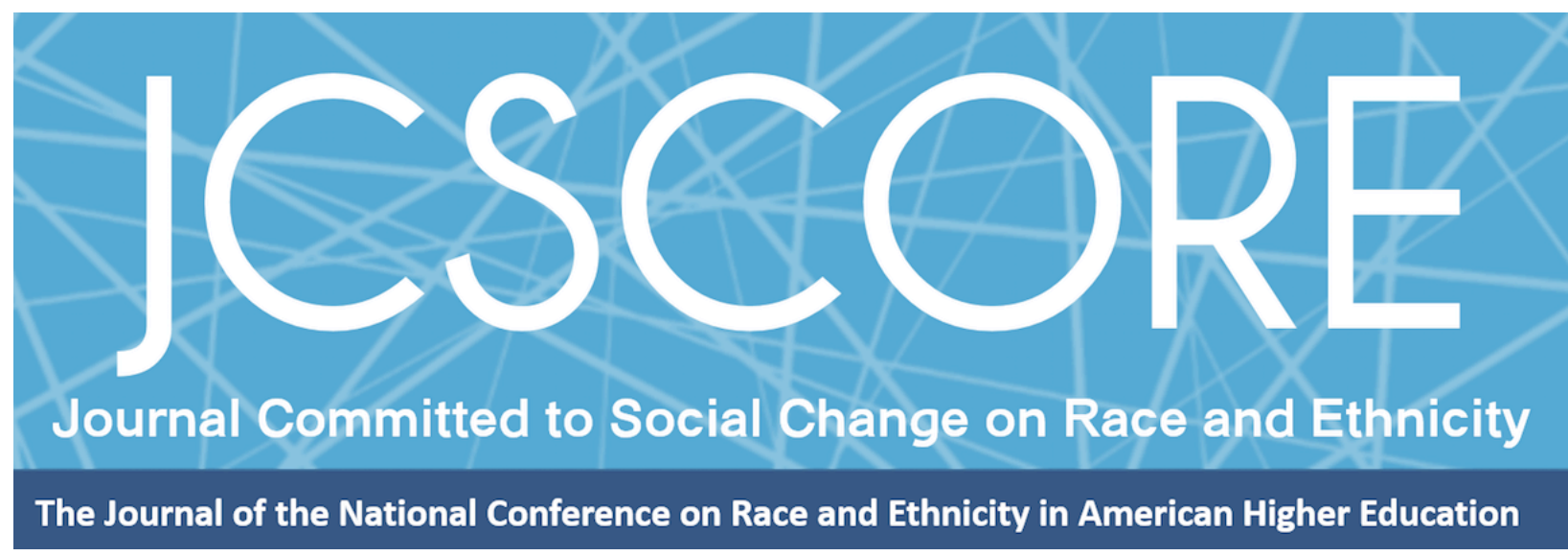

\title{
PICKING A THOUSAND SCABS: COPING IN A-SHARP
}

\author{
Arianne Garcia \\ Stairway to STEM
}

Journal Committed to Social Change on Race and Ethnicity

Volume 6, Issue $1 \mid 2020$

Copyright and Open Access

(c) 2020 Arianne Garcia

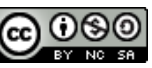

This work is licensed under a Creative Commons Attribution-NonCommercial-ShareAlike 4.0 International License. Permission of the authors is required for distribution and for all derivative works, including compilations and translations. Quoting small sections of text is allowed as long as there is appropriate attribution and the article is used for non-commercial purposes.

The Journal Committed to Social Change on Race and Ethnicity (ISSN 2642-2387) is published by the National Conference on Race and Ethnicity (NCORE), a production of the University of Oklahoma, in partnership with the University of Oklahoma Libraries. 


\section{Picking a Thousand Scabs: Coping in A-Sharp}

Arianne Garcia

Stairway to STEM

In this poem, the author describes a pre- and post-diagnosis review of her life and the effect a lack-of an autism diagnosis had on her focus moving through education whilst being a Latinx youth. The author writes about her experiences coping with communication and social deficits, racism, abuse, and autistic burn-out, to shape a perspective for educators apply for their learning environments.

When I was a kid moving around schools

I tried to objectify my view on the rules

They weren't all the same in all of the places

But I noticed a pattern when it came time to try cases

An impression was made about rules in play spaces

A question was made about rules in gray areas

A session about rules just came off as hysteria

Something was off about the way the world worked

Like I was missing the manual or the coupon book

It was time to read a poem that had Spanish words

And the teacher called on me to read the verse

I was confused because I didn't speak Spanish

I decided speaking up could probably cause damage

So I read the passage

I didn't say the words right and as I was reading

I noticed my class was whiter than me

When another teacher said it was time to "observe"

My peers complained, but I did the inverse

I didn't see an assignment to do

I saw a method to the unpredictable new

To look at the context surrounding the clues

Fourth grade science taught me to describe

I learned how to use facts to decide

I could feel peace when things were as they should be

I connected what I felt to what I would see 
When I thought about my future or what to do for work

I thought about my talents

then the benefits and perks

I thought about meaning and when I got the gist

I decided that I wanted to be a scientist

My parents divorced and I felt the Earth shake

My soul trembling in fear of the quake

Searching for identity

Trying to feel around while the infrastructure was crumbling

Constant chaos of the mind

I locked myself in to protect

I began to solve problems through a slight disconnect

Throughout my teen years I rebelled where I could

Maintaining my grades meant I could stand when I stood

Although every time it came time to choose

Between the devil I didn't and the devil I knew

No matter what choice I would make, I would lose

I stopped trying to find the line

I drew one instead and called it mine

I started using my wits to bemuse

To turn the tables on the hidden rouse

Searching for identity while searching for the rule book

It's hard to focus on studies when you have everywhere to look

I wasn't really the type to act up in school

Although I operated with a different set of tools

"Get a job or quit school band", they told me in a rule session

They were sure I wouldn't get hired, we were in a recession

I smugly announced where I would serve for my crime

I was the new cashier for a place called Pretzel Time

I bought a computer and began to learn

Long after time served, I made it to work

And when I had to quit because of the transit

I knew at that point, I had had it

I sold my time pining for freedom

Reading for hours learning how to leave them

My obsession to get out wearing me thin

Obligations stacked to the height within

I grabbed opportunities as they came by

but my mind doesn't live on the street where they drive 
My first time at Pretzel Time for four months showed me

That the adult world I thought existed was phony

There were two guys there who called me 'spick' and other names

Went through my purse and baritone case

Knew my address and how much I got paid

Like, it was bad

And you know what's so funny?

I would have rather been there

Than at home with my stepdad

Did you catch that I quit because of the bus

And not because those dudes were dangerous?

I could've reported, but I knew it was pointless

They knew where I lived

I couldn't afford to be thoughtless

After a break and when we moved on a different street

I decided to see the woman who hired me

She was happy to see me for summer work

I was happy to see she got rid of those jerks

And yet wasn't long until I began to think

About legal adult things I could do at seventeen

When my grandma finally had a room free

I appreciated it when she offered it to me

My mom acted at first like it was fine

Then she seemed to lose peace of mind

She tried to tighten her grip

But to keep me around she loosened it

These were the things on my mind

Instead of college or the academic grind

And eventually my peace bubble caught fire

Due to the shattered promises of liars

My bubble didn't pop so much as melted

And in the gooey mess, I felt it

I couldn't keep up with all life's deceptions

No matter how quickly I solved its equations

I hated the systems that I was locked in

The actions others made based on my gender and skin

Even after high school I remained angry

Lied to my face all the time and left hanging

Not really sure how to tell who to trust

and how to tell if someone could be dangerous

Communication was always absurd

Did you know there's a structure for nouns, articles and verbs? 
Not any old one that makes lots of sense But the kind of structure that puts listening on offense Using talking to defend instead of explain What ridiculous notions they've made me entertain

l've fallen for for-profit college schemes Twice, in fact, like a deer in high-beams I struggled with paperwork and financial aid laws I couldn't figure out where the heck the line was And I found myself struggling to make ends meet I couldn't understand what I was missing

Then I was told something when I was twenty-five Something that sparked me electric, alive I was informed by a doctor I was autistic and things clicked into place for me in an instant

All the times I misread situations

All the times I misheard conversations

Every wrong proposed explanation

The false dichotomy that became a taunt "Are you sure you can do that?" and "Do whatever you want!"

What they don't tell you when you get diagnosed Is that you review your life in a microscope Imagine living in a house where you know the floor plan, but it's too dark to see Getting a diagnosis was light invoking memories

All the things that I didn't understand Would throw me for a loop when I let it out of hand Understanding that my brain operates a different way Was integral to discoveries l've made and what I now say I wondered why no one thought to test me as a child I get a little ruffled when people say my autism is mild A diagnosis would have changed my life At any age prior to twenty-five

So, the next time you have an autistic someone in your class Take a sec to think about their possible past Use that beat to find support you can give And in that way autistic people can live 